\title{
Haptoglobin Genotype Is a Determinant of Hemoglobin Adducts and Vitamin E Content in HDL
}

\author{
Hagit Goldenstein, ${ }^{1}$ Nina S. Levy, ${ }^{1}$ John Ward, ${ }^{1}$ Tina Costacou, ${ }^{2}$ and Andrew P. Levy $\mathbb{D D}^{1}$ \\ ${ }^{1}$ Technion Faculty of Medicine, Technion Israel Institute of Technology, 1 Efron Street, Haifa, Israel \\ ${ }^{2}$ Department of Epidemiology, University of Pittsburgh, 3512 Fifth Avenue, Pittsburgh, PA 15213, USA
}

Correspondence should be addressed to Andrew P. Levy; alevy@technion.ac.il

Received 14 March 2018; Accepted 2 May 2018; Published 20 May 2018

Academic Editor: Larissa Pernomian

Copyright (C) 2018 Hagit Goldenstein et al. This is an open access article distributed under the Creative Commons Attribution License, which permits unrestricted use, distribution, and reproduction in any medium, provided the original work is properly cited.

\begin{abstract}
Haptoglobin (Hp) is an abundant hemoglobin- (Hb-) binding serum protein and a constituent of the HDL proteome. In man, there exists a common polymorphism at the Hp locus with two common alleles defined by the presence (Hp 2 allele) or absence (Hp 1 allele) of a $1.7 \mathrm{~kb}$ in-frame partial duplication of exons 3 and 4 of the Hp gene. Numerous studies have demonstrated that the Hp $2-2$ genotype is associated with a 3-5-fold increase in vascular disease among individuals with diabetes mellitus (DM). Increased $\mathrm{Hp}-\mathrm{Hb}$ complex has been shown to be associated with the HDL of Hp 2-2 DM individuals. Hb-associated HDL has been proposed to result in the oxidation of HDL and the consumption of antioxidants in HDL, such as vitamin E, rendering the HDL further susceptible to oxidation. In this study, we set out to identify proteins which become cross-linked to Hb in HDL and to measure vitamin $\mathrm{E}$ in $\mathrm{HDL}$ as a function of the $\mathrm{Hp}$ genotype. We report on the identification of a novel $72 \mathrm{kd} \mathrm{Hb}$ reactive species which is cross-linked to HDL and demonstrate that vitamin E in HDL is decreased in Hp 2-2 DM individuals.
\end{abstract}

\section{Introduction}

Haptoglobin ( $\mathrm{Hp}$ ) is a plasma protein which binds free hemoglobin $(\mathrm{Hb})$ and prevents oxidative damage between the heme iron of $\mathrm{Hb}$ and proteins and lipids [1]. The ability of $\mathrm{Hp}$ to neutralize potential oxidation from the heme in $\mathrm{Hb}$ is especially important in DM, where there is increased free extracorpuscular $\mathrm{Hb}$ and increased systemic oxidative stress due to hyperglycemia [2]. In man, there exists a common polymorphism at the Hp locus with two common alleles defined by the presence (Hp 2 allele) or absence (Hp 1 allele) of a $1.7 \mathrm{~kb}$ in-frame duplication of exons 3 and 4 of the Hp gene. Multiple studies have shown that the Hp 2-2 genotype, representing $40 \%$ of the total population, confers a higher risk of developing vascular complications in the setting of DM than other Hp genotypes. For example, the Israel Cardiovascular Vitamin E study (ICARE) [3] and the Strong Heart Study [4] demonstrated that Hp 2-2 DM individuals were three to five times more likely to suffer from cardiovascular disease (CVD) than DM individuals with the Hp 1-1 or 2-1 genotypes.
The mechanism of increased vascular risk in Hp 2-2 individuals is likely due to the impaired ability of the $\mathrm{Hp}$ 2-2 protein to prevent $\mathrm{Hb}$-driven oxidation as compared to the Hp 1-1 protein. This mechanism is supported by results from randomized placebo-controlled clinical trials that have demonstrated that vitamin $\mathrm{E}$ is effective in reducing vascular disease risk of DM Hp 2-2 individuals [5, 6].

High-density lipoprotein (HDL) has been proposed to play a major role in preventing cardiovascular complications by mediating the removal of cholesterol from the macrophage and the vessel wall in a process referred to as reverse cholesterol transport (RCT). However, clinical trials aimed at increasing HDL levels have been largely ineffective in decreasing cardiac events [7]. This has led to suggestions that HDL therapy should be targeted at improving the quality of HDL rather than its quantity [8]. Hp is known to bind to HDL on the ApoAl protein. Studies have shown that more $\mathrm{Hb}$ is associated with HDL in $\mathrm{Hp} 2-2 \mathrm{DM}$ compared to Hp 1-1 DM [5] and that RCT is impaired in Hp 2-2 DM individuals [9]. Furthermore, vitamin E supplementation has been shown to improve HDL-stimulated cholesterol 
efflux and reduced HDL lipid peroxidation in Hp 2-2 DM individuals [5]. In this study we sought to understand and identify how $\mathrm{Hb}$ complexed to HDL might result in oxidative modification of HDL and how this might affect HDL functionality.

\section{Methods}

2.1. Hb Preparation. Blood was drawn from healthy adults. The blood was centrifuged for $10 \mathrm{~min}$ at $188 \times \mathrm{g}$, and the red blood cells (RBCs) were separated from the plasma. RBCs were washed three times by adding phosphate-buffered saline and centrifuging for $10 \mathrm{~min}$ at $188 \times \mathrm{g}$ and lysed with water using ten times the volume of blood. After another centrifugation at $15,000 \times \mathrm{g}$ for $45 \mathrm{~min}$, the hemolysate was separated into aliquots and stored at $-80^{\circ} \mathrm{C}$ until use. Before each experiment, catalase and superoxide dismutase were removed from the $\mathrm{Hb}$ preparation by DEAE-Sepharose anion-exchange chromatography [10].

2.2. Hp Preparation. Hp from plasma donated by 4 healthy individuals (2 samples for each $\mathrm{Hp} \mathrm{1-1} \mathrm{and} \mathrm{Hp} \mathrm{2-2)} \mathrm{was}$ affinity purified using a goat anti-Hp antibody column. Hp was stored at $-80^{\circ} \mathrm{C}$ until use [11].

2.3. HDL Purification. HDL was purified by two different methods: first, by using macroultracentrifugation as was described by Asleh et al. [5] and second, by using density gradient microultracentrifugation. Briefly, plasma $(500 \mu \mathrm{l})$ was incubated with $20 \mu \mathrm{l}$ of a heparin solution $(5000 \mathrm{U} / \mathrm{ml})$ and $50 \mu \mathrm{l}$ of $1 \mathrm{M} \mathrm{MnCl}_{2}$ at $4^{\circ} \mathrm{C}$. After $30 \mathrm{~min}$ of incubation, the samples were centrifuged for $20 \mathrm{~min}$ at $1500 \times \mathrm{g}$ and $4^{\circ} \mathrm{C}$. The upper layer was transferred to a microultracentrifuge tube and $300 \mu \mathrm{l}$ of $1.95 \mathrm{M} \mathrm{NaCl}$ and $76.5 \mathrm{M}$ of $\mathrm{NaBr}$ solution $\left(1.478 \mathrm{~g} / \mathrm{cm}^{3}\right)$ were added to it. The tubes were centrifuged for 2.5 hours at $16^{\circ} \mathrm{C}$ and $120,000 \times \mathrm{g}$. After the centrifugation, $300 \mu \mathrm{l}$ from the upper layer were removed and dialyzed overnight against a $1.006 \mathrm{~g} / \mathrm{cm}^{3} 0.186 \mathrm{M} \mathrm{NaCl}$ solution with $1.26 \mathrm{mM}$ EDTA. The samples were stored at $4^{\circ} \mathrm{C}$.

2.4. $H D L$ and $H b-H p$ Complex Oxidation. Eight different $\mathrm{Hb}-\mathrm{Hp}$ complexes were formed by incubating $\mathrm{Hb}$ and $\mathrm{Hp}$ (1:1 molar ratio) for $15 \mathrm{~min}$ at $25^{\circ} \mathrm{C}$ and then incubating with $\mathrm{HDL}$ for one hour. $\mathrm{H}_{2} \mathrm{O}_{2}(1: 5$ molar excess) was added to $\mathrm{Hb}$-Hp complexes for $30 \mathrm{~min}$ at $37^{\circ} \mathrm{C}$ and the samples were passed through a PD-10 column, in order to remove $\mathrm{H}_{2} \mathrm{O}_{2}$. The samples were diluted to a final concentration of $500 \mathrm{nM}$ and were loaded on SDS-PAGE gels and transferred onto a PVDF membrane. In order to prevent nonspecific antigen binding, the membrane was incubated with $1 \%$ milk for $30 \mathrm{~min}$ in $25^{\circ} \mathrm{C}$. A rabbit anti-Hb antibody (DAKO, dilution $1: 2000)$ was added overnight: incubation was performed at $4^{\circ} \mathrm{C}$. After washing the membrane for 10 min $\times 3$ times with TBST, polyclonal goat anti-rabbit HRP-conjugated antibody (DAKO, dilution $1: 2000$ ) was added for $30 \mathrm{~min}$ at $25^{\circ} \mathrm{C}$. Proteins were identified and quantified using an ECL substrate. The membrane was washed with a reblot buffer purchased from Mercury Scientific \& Industrial Products Ltd. (Rosh Ha-ayin, Israel), and the procedure was repeated with rabbit anti-Hp antibody. The potential role of $\mathrm{Hb}$-induced tyrosine radicals in generating $\mathrm{Hb}$-HDL cross-links was tested by studying the effect of different concentrations (10-400 nM) of hydroxyurea on $\mathrm{HDL} \mathrm{Hb}$ cross-linking.

2.5. Sequencing of the $\mathrm{Hb}$ Immunoreactive $72 \mathrm{kd}$ Band in $H D L$. Two samples of $72 \mathrm{kd}$ bands prepared by two different methods were sequenced. First, the $72 \mathrm{kd}$ region of a SDSPAGE gel of HDL in which the $72 \mathrm{kd}$ band was previously shown to be prominent was excised, then the protein extracted was digested by trypsin, analyzed by LC-MS/MS on LTQ-Orbitrap (Thermo), and identified by Discoverer software against the human part of the Uniprot database and a decoy database (in order to determine the false discovery rate). Second, HDL samples were analyzed by $2 \mathrm{D}$ gel electrophoresis. For the first dimension, Immobiline DryStrip NL ( $\mathrm{pH} 3-7,13 \mathrm{~cm})$ (GE) was used. The strips were rehydrated in rehydration solution (40 mM DDT, $4 \%$ CHAPS, $8 \mathrm{M}$ urea, $2 \mathrm{M}$ thiourea, $2 \% \mathrm{IPG}$, and $1 \mu \mathrm{l}$ of $2 \%$ bromophenol blue). Isoelectric focusing was done with an Ettan IPGphor3 (GE) and maintained at $20^{\circ} \mathrm{C}$. The program was $150 \mathrm{~V}$ for $4 \mathrm{~h}, 10 \mathrm{~h}$ gradient from 150 to $1000 \mathrm{~V}$, $4 \mathrm{~h}$ gradient from 1000 to $2000 \mathrm{~V}, 2 \mathrm{~h}$ at $2000 \mathrm{~V}, 3 \mathrm{~h}$ gradient from 2000 to $3000 \mathrm{~V}$, and finally $1 \mathrm{~h}$ at $3000 \mathrm{~V}$ (total, $26,850 \mathrm{Vh})$. The strips were equilibrated for $15 \mathrm{~min}$ in $0.05 \mathrm{M}$ Tris- $\mathrm{HCl}$ ( $\mathrm{pH} 8.8$ ), $6 \mathrm{M}$ urea, 30\% ( $v / v)$ glycerol, $2 \%$ $(w / v)$ SDS, and $20 \mathrm{mM}$ DTT and then equilibrated for $15 \mathrm{~min}$ in the same buffer but containing $125 \mathrm{mM}$ iodoacetamide in place of DTT. The equilibrated strips were applied to a vertical 8\% SDS page used on S.E. 600 Ruby (Amersham Biosciences). The gel was silver stained in order to identify the protein spots which were excised and sent for sequencing.

2.6. Measurement of Vitamin E ( $\alpha$-Tocopherol) in HDL. HDL from 81 diabetic patients was purified by density gradient microultracentrifugation as described above. Aliquots $(500 \mu \mathrm{l})$ of $\mathrm{HDL}$ were mixed with $500 \mu \mathrm{l}$ of extractant and the samples shaken vigorously (vortexed for $10 \mathrm{~min}$ ) with $6 \mathrm{ml}$ of petroleum ether. Samples were then centrifuged at $800 \mathrm{~g}$ for $5 \mathrm{~min}$ and the supernatants collected and divided into two equal aliquots. One aliquot was dried under nitrogen and stored at $-70^{\circ} \mathrm{C}$ prior to analysis by HPLC. The other aliquot was dried under nitrogen, resuspended in $300 \mu \mathrm{l}$ of ethanol and the absorbance at $450 \mathrm{~nm}$ read by a VP Supersystem analyzer (Abbott). To measure $\alpha$-tocopherol, the aliquot was resuspended in $50 \mu \mathrm{l}$ of ethanol and $25 \mu \mathrm{l}$ analyzed by HPLC. The column used was a Microsorb-MV C18 $(5 \mu \mathrm{m}$; $4.6 \mathrm{~mm} \times 25 \mathrm{~cm}$; Rainin) and the solvent was methanol flowing at $2 \mathrm{ml} / \mathrm{min}$. The HPLC was a model 1090 (HewlettPackard) and the detector a UV diode array model 1040 (Hewlett-Packard). Components were monitored at $290 \mathrm{~nm}$ and the calculations were based on peak areas and the relative intensities determined using mixtures of authentic standards. The coefficient of variation between runs was $2.8 \%$ for $\alpha$-tocopherol [12].

2.7. Reverse Cholesterol Transport (RCT) Assay. This assay, assessing the ability of serum from an individual to promote 


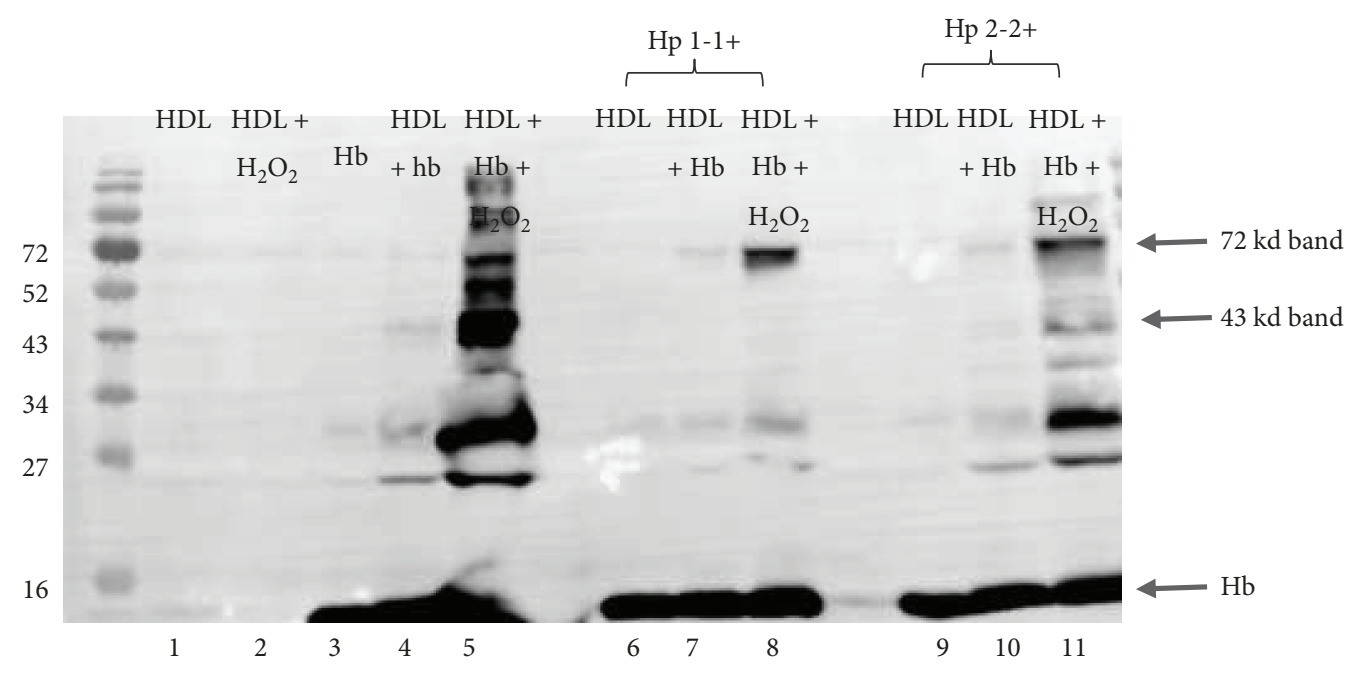

FIgure 1: Detection of Hb cross-links on HDL by Western blot. Hp 1-1 or 2-2 was incubated with $\mathrm{Hb}(1: 1$ ratio) creating a Hp-Hb complex. These complexes, with or without $\mathrm{H}_{2} \mathrm{O}_{2}$ (1:10 molar excess), were added to HDL from healthy volunteers, loaded on a SDS-PAGE gel and were transferred to a PVDF membrane. (1) HDL, (2) $\mathrm{HDL}+\mathrm{H}_{2} \mathrm{O}_{2}$, (3) $\mathrm{Hb}$, (4) $\mathrm{HDL}+\mathrm{Hb}$, (5) $\mathrm{HDL}+\mathrm{Hb}+\mathrm{H}_{2} \mathrm{O}_{2}$, (6) $\mathrm{HDL}+\mathrm{Hp} 1-1$, (7) $\mathrm{HDL}+\mathrm{Hb} / \mathrm{Hp} 1-1$, (8) $\mathrm{HDL}+\mathrm{Hb} / \mathrm{Hp} 1-1+\mathrm{H}_{2} \mathrm{O}_{2}$, (9) $\mathrm{HDL}+\mathrm{Hp} 2-2$, (10) $\mathrm{HDL}+\mathrm{Hb} / \mathrm{Hp} 2-2$, and (11) $\mathrm{HDL}+\mathrm{Hb} / \mathrm{Hp} 2-2+\mathrm{H}_{2} \mathrm{O}_{2}$.

cholesterol efflux from macrophages, was described previously by Asleh et al. [9]. Briefly, J774 cells were seeded onto 24-well plates in DMEM medium with 8\% FCS for 48 hours. Cells were incubated with ${ }^{3} \mathrm{H}$-labeled cholesterol $(0.3 \mu \mathrm{C} / \mathrm{ml})$ in serum-free DMEM supplemented with $1 \% \mathrm{BSA}$ in $37^{\circ} \mathrm{C}$ for 16 hours. After 2 washes with PBS, the cells were exposed to DMEM supplemented with oxidized HDL, with or without $\mathrm{Hb} / \mathrm{Hp}$ complex samples for 3 hours. Medium was collected in scintillation tubes, and cells were incubated overnight with $0.1 \mathrm{M} \mathrm{NaOH}$ in $37^{\circ} \mathrm{C}$. Radioactivity was measured both in cells and media to assess the RCT activity of serum.

2.8. Ethics Committee Approval to Use Human Samples. The use of human serum samples in this study was approved by the University of Pittsburgh Institutional Review Board (IRB, protocol number PRO09010072).

2.9. Statistical Analysis. Data are reported as the mean \pm SD. In experiments comparing $\mathrm{Hp} \mathrm{1-1}$ and $\mathrm{Hp} 2-2$ only, the Student's $t$-test was used. In experiments comparing differences among the three Hp types, we used one-way ANOVA followed by post hoc comparisons between two specific Hp genotypes using Bonferroni's adjustment for multiple comparisons. A $p$ value less than 0.05 was considered as statistically significant.

\section{Results}

3.1. Hb Cross-Linking with HDL Is Hp Genotype Dependent. We assessed by Western blot the ability of $\mathrm{Hp} \mathrm{1-1-Hb}$ or $\mathrm{Hp}$ 2-2-Hb complexes to become cross-linked with HDL in the presence of $\mathrm{H}_{2} \mathrm{O}_{2}$ (Figure 1). In native HDL (lane 1), we found a weak $\mathrm{Hb}$-immunoreactive $72 \mathrm{kd}$ band that increased with the addition of $\mathrm{Hb}$ and $\mathrm{H}_{2} \mathrm{O}_{2}$, with or without $\mathrm{Hp}$ (lanes 5,8 , and 11). In the presence of $\mathrm{Hb}$ and $\mathrm{H}_{2} \mathrm{O}_{2}$, we observed additional bands (ranging from $25 \mathrm{kd}$ to $52 \mathrm{kd}$ ) (lane 5) that indicated the formation of other $\mathrm{Hb}$ cross-linked species in $\mathrm{HDL}$ induced by $\mathrm{Hb}$. The addition of $\mathrm{Hp}$ to this system reduced the intensities of several of these Hb HDL adducts, most notably a $43 \mathrm{kd}$ species (average \pm SD: $0.03 \pm 0.04$ (Hp 1-1), 0.16 \pm 0.13 (Hp 2-2); median: 0.012 (Hp 1-1), 0.18 (Hp 2-2); post hoc pairwise comparison $p$ value $=0.02$, $n=8$, comparing $\mathrm{HDL}+\mathrm{Hb}+\mathrm{Hp} \mathrm{1-1}+\mathrm{H}_{2} \mathrm{O}_{2}$ versus $\mathrm{HDL}+$ $\mathrm{Hb}+\mathrm{Hp} 2-2+\mathrm{H}_{2} \mathrm{O}_{2}$ ). The differences in band intensities between $\mathrm{HDL}$ incubated with $\mathrm{Hb}, \mathrm{H}_{2} \mathrm{O}_{2}$, and either $\mathrm{Hp}$ 1-1 or Hp 2-2 (lanes 8,11) are summarized in Figure 2.

3.2. Hydroxyurea Prevents $\mathrm{Hb}$ Cross-Linking to $\mathrm{HDL}$. Hydroxyurea, a tyrosine radical blocker [13], was added to the $\mathrm{Hb}-\mathrm{H}_{2} \mathrm{O}_{2}-\mathrm{HDL}$ incubation (Figure 3). The $43 \mathrm{kd}$ band (arrow) is seen in HDL with $\mathrm{Hb}$ and $\mathrm{H}_{2} \mathrm{O}_{2}$ (lane 2), but it is inhibited by the addition of hydroxyurea (lanes 6-9).

3.3. HDL Reverse Cholesterol Transport Is Impaired When HDL Is Oxidized. HDL was incubated with Hp 1-1-Hb or Hp 2-2-Hb complexes, and RCT stimulated by this HDL was measured (Figure 4). In the presence of Hb-Hp 1-1 complexes, the ability of HDL to promote cholesterol efflux was significantly higher than with HDL complexed with $\mathrm{Hb}-\mathrm{Hp}$ 2-2 (average \pm SD: $13.3 \pm 3.8$ and $8.6 \pm 2.9$ for $\mathrm{Hp} 1-1$ and Hp 2-2, respectively; median 13.9 and 7.9 for $\mathrm{Hp} \mathrm{1-1} \mathrm{and}$ $\mathrm{Hp} 2-2$, respectively, ${ }^{*} p$ value $<0.001$ ( $t$-test) comparing $\mathrm{Hb} / \mathrm{Hp}$ 1-1 versus $\mathrm{Hb} / \mathrm{Hp} 2-2, n=8)$.

3.4. Identification of the Proteins in the Hb Cross-Linked Species of Native HDL. We investigated the presence of $\mathrm{Hb}$ cross-linked proteins on the HDL of individuals with different Hp genotypes. HDL was purified using a microultracentrifugation technique and subjected to PAGE. Western blot analysis using anti- $\mathrm{Hb}$ (see Figure 5) showed a $72 \mathrm{kd}$ band (red arrow) which varied in intensity between individuals.

We hypothesized that the $72 \mathrm{kd}$ species might contain $\mathrm{Hb}$ cross-linked to ApoA1 or $\mathrm{Hp}$. We therefore performed 
$\mathrm{Hb}$ cross-links on HDL

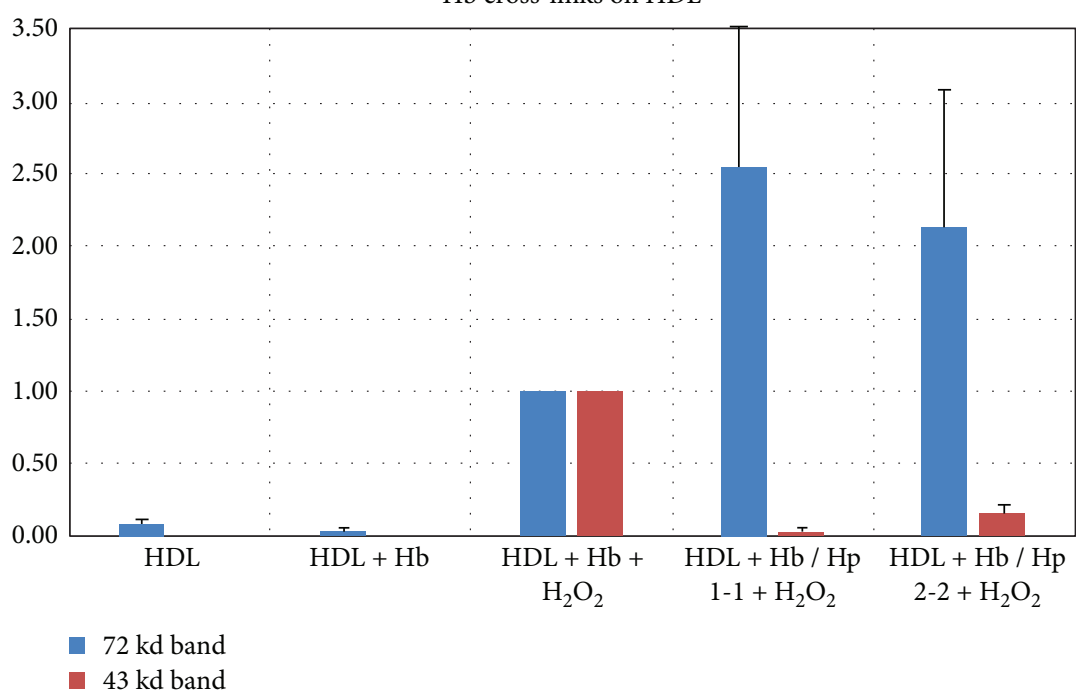

Figure 2: Measurement of $\mathrm{Hb}$ adducts with HDL. The $72 \mathrm{kd}$ and $43 \mathrm{kd} \mathrm{Hb}$ immunoreactive bands were analyzed by ImageMaster, and the results were normalized to that obtained with $\mathrm{HDL}+\mathrm{Hb}+\mathrm{H}_{2} \mathrm{O}_{2}$ alone. The experiment was repeated eight times with 4 separate $\mathrm{Hp}$ preparations of each type (1-1 and 2-2) with each Hp preparation assessed twice. Data is reported as mean \pm SD.

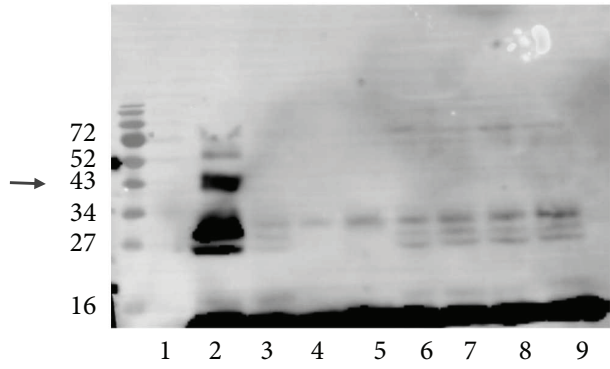

Figure 3: Hydroxyurea addition to $\mathrm{HDL}, \mathrm{Hb}$, and $\mathrm{H}_{2} \mathrm{O}_{2}$ inhibits $\mathrm{Hb}$ cross-link formation. HDL (obtained from the plasma of healthy volunteers), $\mathrm{Hb}$, and $\mathrm{H}_{2} \mathrm{O}_{2}$ (1:10 ratio) were incubated with different concentrations of hydroxyurea for 1 hour. The samples were loaded on SDS-PAGE gel, transferred to a PVDF membrane, and stained with anti-Hb antibody. The sample order is (1) HDL, (2) $\mathrm{HDL}+\mathrm{Hb}+\mathrm{H}_{2} \mathrm{O}_{2}$, (3) $\mathrm{HDL}+\mathrm{Hb}$, (4) $\mathrm{Hb}$, (5) $\mathrm{Hb}+\mathrm{H}_{2} \mathrm{O}_{2}$, (6) $\mathrm{HDL}+\mathrm{Hb}+\mathrm{H}_{2} \mathrm{O}_{2}+$ hydroxyurea $(400 \mathrm{nM}),(7) \mathrm{HDL}+\mathrm{Hb}+\mathrm{H}_{2} \mathrm{O}_{2}$ + hydroxyurea $(200 \mathrm{nM})$, (8) $\mathrm{HDL}+\mathrm{Hb}+\mathrm{H}_{2} \mathrm{O}_{2}+$ hydroxyurea $(100 \mathrm{nM})$, and (9) $\mathrm{HDL}+\mathrm{Hb}+\mathrm{H}_{2} \mathrm{O}_{2}+$ hydroxyurea $(10 \mathrm{nM})$.

Western blot analysis of the same membrane with antiapoA1 and anti-Hp antibodies and found $72 \mathrm{kd}$ anti-Apo A1 reactive bands but no $72 \mathrm{kd}$ anti-Hp band (see Figure 6) suggesting that this $72 \mathrm{kd}$ species contained Apo A1 but not Hp. Sequence analysis of the excised $72 \mathrm{kd}$ band confirmed the presence of $\alpha$ and $\beta$ subunits of $\mathrm{Hb}$ and Apo A1 as being part of this $72 \mathrm{kd}$ complex.

3.5. Quantitation of the $72 \mathrm{kd} \mathrm{Hb}$ Immunoreactive Band in Hp 1-1 and Hp 2-2 DM Individuals. The amount of the $72 \mathrm{kd}$ species was measured in 52 diabetic individuals by Western blot analysis. We found no significant difference in the amount of the $72 \mathrm{kd}$ complex in individuals with the different $\mathrm{Hp}$ types (average $\pm \mathrm{SD}$ : $0.12 \pm 1.4$

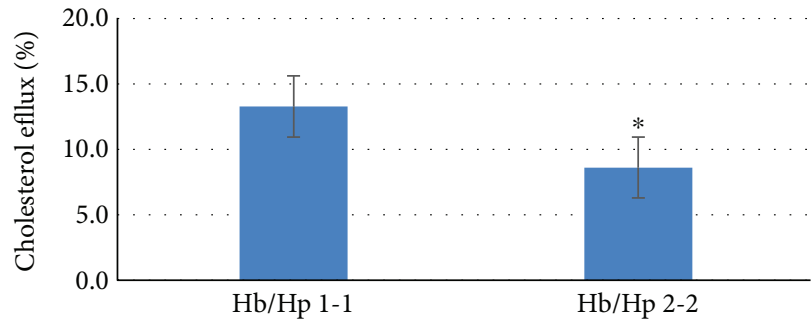

Figure 4: The effect of Hp genotypes on the cholesterol efflux of oxidized HDL. Hb-Hp1-1 or Hb-Hp 2-2 complexes were incubated with the same HDL preparation in the presence of $\mathrm{H}_{2} \mathrm{O}_{2}(1: 10$ molar excess) for 1 hour. After incubation, the samples were added to macrophages and the efflux of $\left({ }^{3} \mathrm{H}\right)$ cholesterol from macrophages was measured ( $*$ indicates the $p$ value $<0.001$ ( $\mathrm{t}$-test) comparing $\mathrm{Hb} / \mathrm{Hp}$ 1-1 versus $\mathrm{Hb} / \mathrm{Hp} 2-2$ ).

(Hp 1-1), $1.43 \pm 2.7$ (Hp 2-2); median: 0.07 (Hp 1-1), 0.3 $($ Hp 2-2), $n=17, p$ value $=0.19$ ( $t$-test) comparing Hp 1-1 versus Hp 2-2).

3.6. Quantification of Vitamin E Levels on HDL. The amount of vitamin $\mathrm{E}$ in the HDL from 73 DM individuals who participated in the HapE study was measured (blood collected at entry into the study), and the average vitamin E levels in HDL segregated by Hp type are seen in Table 1. We found a significant difference in HDL vitamin E levels between the three Hp genotypes (overall $p$ value for difference between groups $=0.0165($ ANOVA $))$. There was a $43 \%$ lower vitamin $\mathrm{E}$ level in HDL from $\mathrm{Hp}$ 2-2 DM individuals as compared to $\mathrm{Hp}$ 1-1 DM individuals (post hoc pairwise comparison between $\mathrm{Hp} 1-1$ versus $\mathrm{Hp} 2-2 p$ value $=0.0026$ $(t$-test $))$. There was no significant difference in total serum vitamin $\mathrm{E}$ by $\mathrm{Hp}$ type (overall $p$ value for difference between groups $=0.07($ ANOVA $))[14]$. 


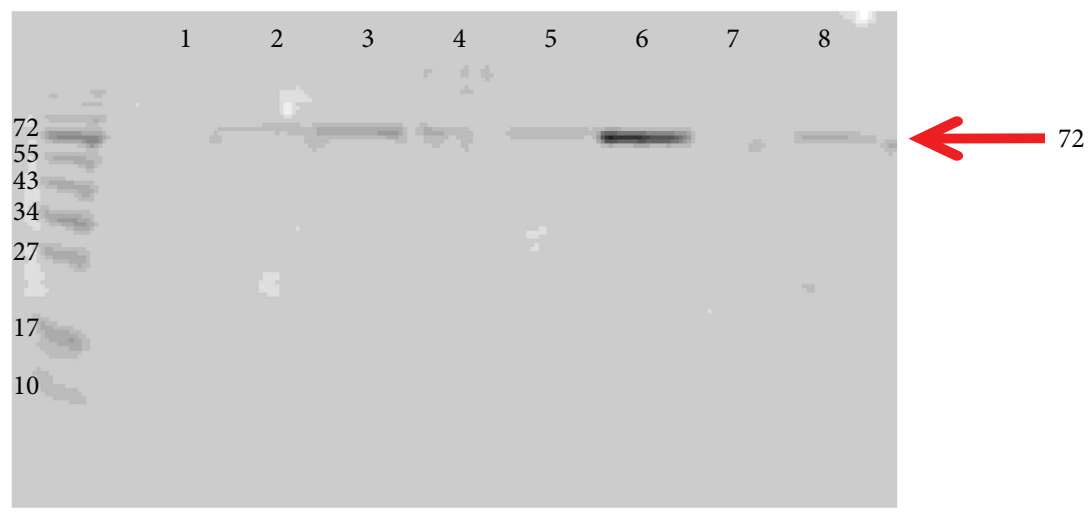

Figure 5: Detection of a $72 \mathrm{kd} \mathrm{Hb}$ immunoreactive band on native HDL. Eight HDL samples from diabetic individuals were loaded on an SDS-PAGE gel and transferred to a PVDF membrane. Anti-Hb antibody was added to the membrane, as described in Methods. A $72 \mathrm{kd}$ band was seen (arrow) indicating the presence of a cross-linked species.

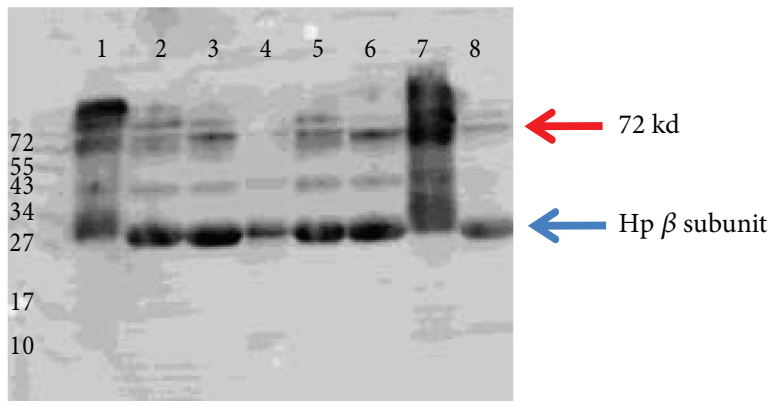

(a)

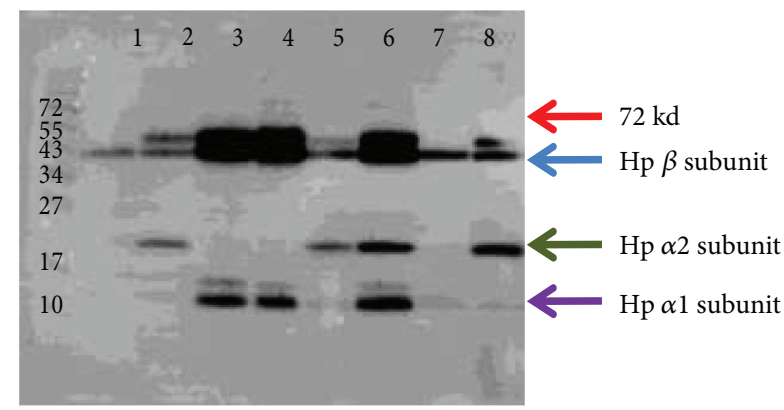

(b)

FIgURE 6: (a-b) Detection of cross-links on HDL with anti-ApoA1 and Hp antibodies. The same membrane from Figure 5 was reblotted and was incubated with anti-Apo A1 (panel a) or anti-Hp (panel b).

TABle 1: Measurement of vitamin E levels in HDL from diabetic individuals.

\begin{tabular}{lcc}
\hline & $\begin{array}{c}\text { Average } \pm \text { SD vitamin E levels } \\
(\mu \mathrm{g} / \mathrm{mg} \text { HDL })\end{array}$ & \% change versus Hp 1-1 \\
\hline Hp 1-1 & $1.18 \pm 0.62$ & - \\
Hp 2-1 & $0.99 \pm 0.63$ & $-17 \%$ \\
Hp 2-2 & $0.67 \pm 0.62$ & $-43 \%$ \\
\hline
\end{tabular}

Comparison between vitamin E levels in HDL from diabetic individuals with different $\mathrm{Hp}$ phenotypes. There was a significant difference in HDL vitamin $\mathrm{E}$ levels between the three Hp genotypes (overall $p$ value for difference between groups $=0.0165$ (ANOVA), post hoc comparison between Hp 1-1 and $\mathrm{Hp} 2-2 p$ value $=0.0026$ ( $t$-test $))$.

\section{Discussion}

We have shown here that $\mathrm{Hb}$ can form protein cross-links with HDL and that Hp 2-2 is inferior to Hp 1-1 in inhibiting the formation of these adducts with HDL. Previous work had established that there was more $\mathrm{Hb}$ associated with the HDL of Hp 2-2 DM individuals and that the HDL of these individuals is dysfunctional [5]. We have demonstrated here that the increased association of $\mathrm{Hb}$ and oxidative damage by $\mathrm{Hb}$ in $\mathrm{Hp}$ 2-2 can be recapitulated in vitro with purified $\mathrm{Hp}$, $\mathrm{Hb}$, and HDL. This suggests that it may be possible to use such an in vitro system to identify drugs that may similarly prevent $\mathrm{HDL} \mathrm{Hb}$ adducts in vivo.

We have not definitively identified the nature of the protein adducts formed between $\mathrm{Hb}$ and HDL. MS sequencing of the $72 \mathrm{kd} \mathrm{Hb}$ immunoreactive band which appears in native HDL suggests that this complex includes apoAl. A $43 \mathrm{kd}$ adduct of $\mathrm{Hb}$ with $\mathrm{HDL}$ and which is $\mathrm{Hp}$ type specific appears to also be an adduct of Apo $\mathrm{Al}$ and $\mathrm{Hb}$ and this is consistent with the MW of these two proteins $(27 \mathrm{kd}$ and $16 \mathrm{kd})$. The Hp-binding site is on helix 6 of Apo-A1, and overlaps with the binding site of lecithin acetyl transferase (LCAT) on Apo-A1. This overlapping causes the displacement of LCAT and has been shown to result in an inhibition of LCAT cholesterol esterification rate in vitro and decreased LCAT activity significantly lower in $\mathrm{Hp} 2-2$ diabetic individuals than in Hp 1-1 diabetic individuals [9]. This theory is consistent with the significant reduction in cholesterol efflux ability noted for HDL oxidized with Hp 2-2 (Figure 4). This hypothesis is further supported by Watanabe et al. who demonstrated that the $\mathrm{Hp}$ presence on HDL allows $\mathrm{Hb}$ to associate with HDL, and the amount of Hb in HDL increases HDL proinflammatory properties in CHD patients [14]. It will be of great interest to determine if the presence of the $72 \mathrm{kd} \mathrm{Hb}$ reactive species or the propensity of a given patient to form the $43 \mathrm{kd}$ adduct is predictive of cardiovascular events and may therefore serve as a targetable biomarker. 
We have also demonstrated for the first time that the concentration of vitamin E in HDL is Hp type dependent. In the patients in whom this was measured we had previously reported that total serum vitamin $\mathrm{E}$ was not Hp type dependent. The decreased amount of vitamin E in the HDL of Hp 2-2 individuals may be due to its increased consumption by the $\mathrm{Hb}$ which is bound to it. Similarly, Ji et al. have shown an association between the elevation of plasma $\mathrm{Hb}$ levels as a result of hemolysis in sickle cell anemia and decreased antioxidant function of HDL. This study extends the relevance of our findings to other diseases [15].

Supplementation of vitamin E would be expected to replenish vitamin $\mathrm{E}$ within $\mathrm{HDL}$ and thereby provide protection. These data may explain why vitamin $\mathrm{E}$ has been shown to improve HDL function in $\mathrm{Hp}$ 2-2 individuals but not in other Hp types and why vitamin $\mathrm{E}$ may be protective against CVD in Hp 2-2 but not in the other Hp types. It would be interesting to know if baseline HDL vitamin E levels were predictive of benefit from antioxidant therapy in recent antioxidant trials.

It is increasingly being understood that HDL function may be more important than HDL mass. Increasing HDL mass in individuals in whom HDL is dysfunctional may actually be harmful [7]. We have shown that the adducts formed here result in functional changes in the HDL. Ongoing studies are addressing whether these adducts can be used as surrogate markers for HDL functionality.

\section{Data Availability}

All data arising from this study are contained within the manuscript.

\section{Conflicts of Interest}

The institution of Andrew Levy owns a patent which claims to predict that vitamin $\mathrm{E}$ can reduce CVD in $\mathrm{Hp}$ 2-2 DM individuals.

\section{Acknowledgments}

This work was funded by grants from the Israel Science Foundation and the Rappaport Foundation Research Fund to APL and a grant from the American Diabetes Association to TC.

\section{References}

[1] H. F. Bunn and J. H. Jandl, "Exchange of heme among hemoglobin molecules," Proceedings of the National Academy of Sciences of the United States of America, vol. 56, no. 3, pp. 974-978, 1966.

[2] G. K. Kolluru, S. C. Bir, and C. G. Kevil, "Endothelial dysfunction and diabetes: effects on angiogenesis, vascular remodeling, and wound healing," International Journal of Vascular Medicine, vol. 2012, Article ID 918267, 30 pages, 2012.

[3] U. Milman, S. Blum, C. Shapira et al., "Vitamin E supplementation reduces cardiovascular events in a subgroup of middle-aged individuals with both type 2 diabetes mellitus and the haptoglobin 2-2 genotype: a prospective double- blinded clinical trial," Arteriosclerosis, Thrombosis, and Vascular Biology, vol. 28, no. 2, pp. 341-347, 2007.

[4] A. P. Levy, I. Hochberg, K. Jablonski et al., "Haptoglobin phenotype is an independent risk factor for cardiovascular disease in individuals with diabetes: the Strong Heart Study," Journal of the American College of Cardiology, vol. 40, no. 11, pp. 1984-1990, 2002.

[5] R. Asleh, S. Blum, S. Kalet-Litman et al., "Correction of HDL dysfunction in individuals with diabetes and the haptoglobin 2-2 genotype," Diabetes, vol. 57, no. 10, pp. 2794-2800, 2008.

[6] A. P. Levy, H. C. Gerstein, R. Miller-Lotan et al., "The effect of vitamin $\mathrm{E}$ supplementation on cardiovascular risk in diabetic individuals with different haptoglobin phenotypes," Diabetes Care, vol. 27, no. 11, p. 2767, 2004.

[7] J. Salazar, L. C. Olivar, E. Ramos, M. Chávez-Castillo, J. Rojas, and V. Bermúdez, "Dysfunctional high-density lipoprotein: an innovative target for proteomics and lipidomics," Cholesterol, vol. 2015, Article ID 296417, 22 pages, 2015.

[8] K. M. Ali, A. Wonnerth, K. Huber, and J. Wojta, "Cardiovascular disease risk reduction by raising HDL cholesterol current therapies and future opportunities," British Journal of Pharmacology, vol. 167, no. 6, pp. 1177-1194, 2012.

[9] R. Asleh, R. Miller-Lotan, M. Aviram et al., "Haptoglobin genotype is a regulator of reverse cholesterol transport in diabetes in vitro and in vivo," Circulation Research, vol. 99, no. 12, pp. 1419-1425, 2006.

[10] M. Melamed-Frank, O. Lache, B. I. Enav et al., "Structurefunction analysis of the antioxidant properties of haptoglobin," Blood, vol. 98, no. 13, pp. 3693-3698, 2001.

[11] R. Asleh, J. Ward, N. S. Levy, S. Safuri, D. Aronson, and A. P. Levy, "Haptoglobin genotype-dependent differences in macrophage lysosomal oxidative injury," The Journal of Biological Chemistry, vol. 289, no. 23, pp. 16313-16325, 2014.

[12] Y. Hirowatari, H. Yoshida, H. Kurosawa, D. Manita, and N. Tada, "Automated measurement method for the determination of vitamin E in plasma lipoprotein classes," Scientific Reports, vol. 4, no. 1, article 4086, 2015.

[13] T. Costacou, A. P. Levy, R. G. Miller et al., "Effect of vitamin E supplementation on HDL function by haptoglobin genotype in type 1 diabetes: results from the HapE randomized crossover pilot trial," Acta Diabetologica, vol. 53, no. 2, pp. 243-250, 2016.

[14] J. Watanabe, V. Grijalva, S. Hama et al., "Hemoglobin and its scavenger protein haptoglobin associate with ApoA-1containing particles and influence the inflammatory properties and function of high density lipoprotein," The Journal of Biological Chemistry, vol. 284, no. 27, pp. 18292-18301, 2009.

[15] X. Ji, Y. Feng, H. Tian et al., "The mechanism of proinflammatory HDL generation in sickle cell disease is linked to cell-free hemoglobin via haptoglobin," PLoS One, vol. 11, no. 10, article e0164264, 2016. 


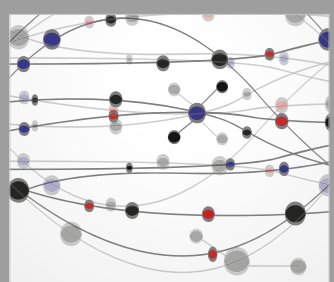

The Scientific World Journal
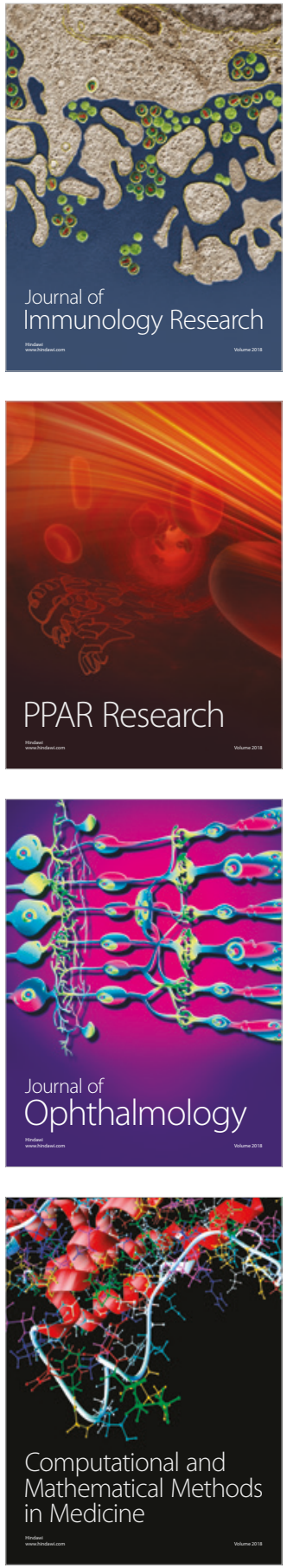

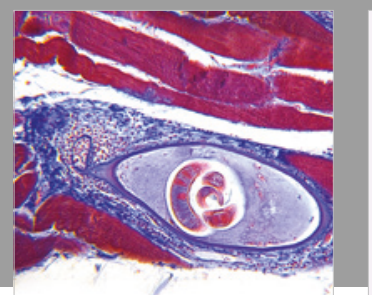

Gastroenterology Research and Practice

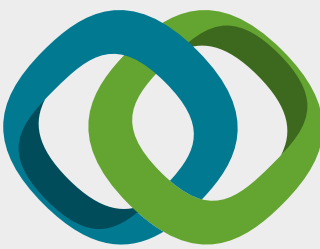

\section{Hindawi}

Submit your manuscripts at

www.hindawi.com
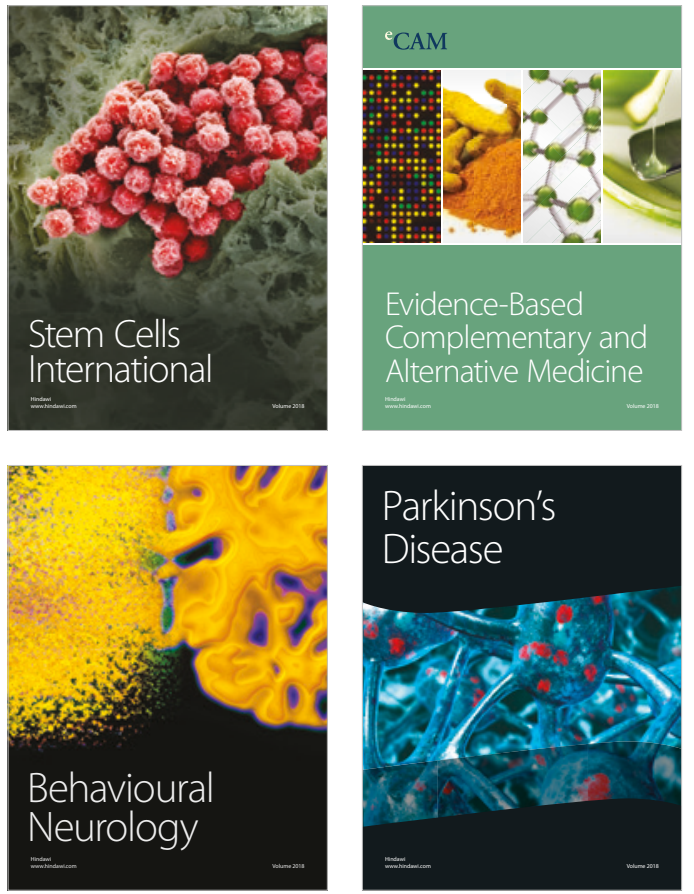

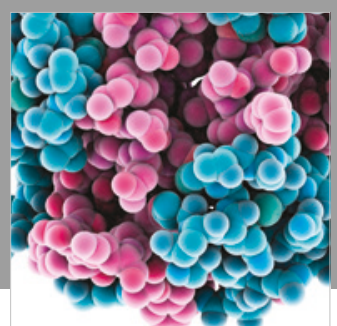

ournal of

Diabetes Research

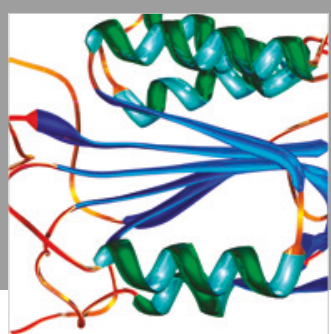

Disease Markers
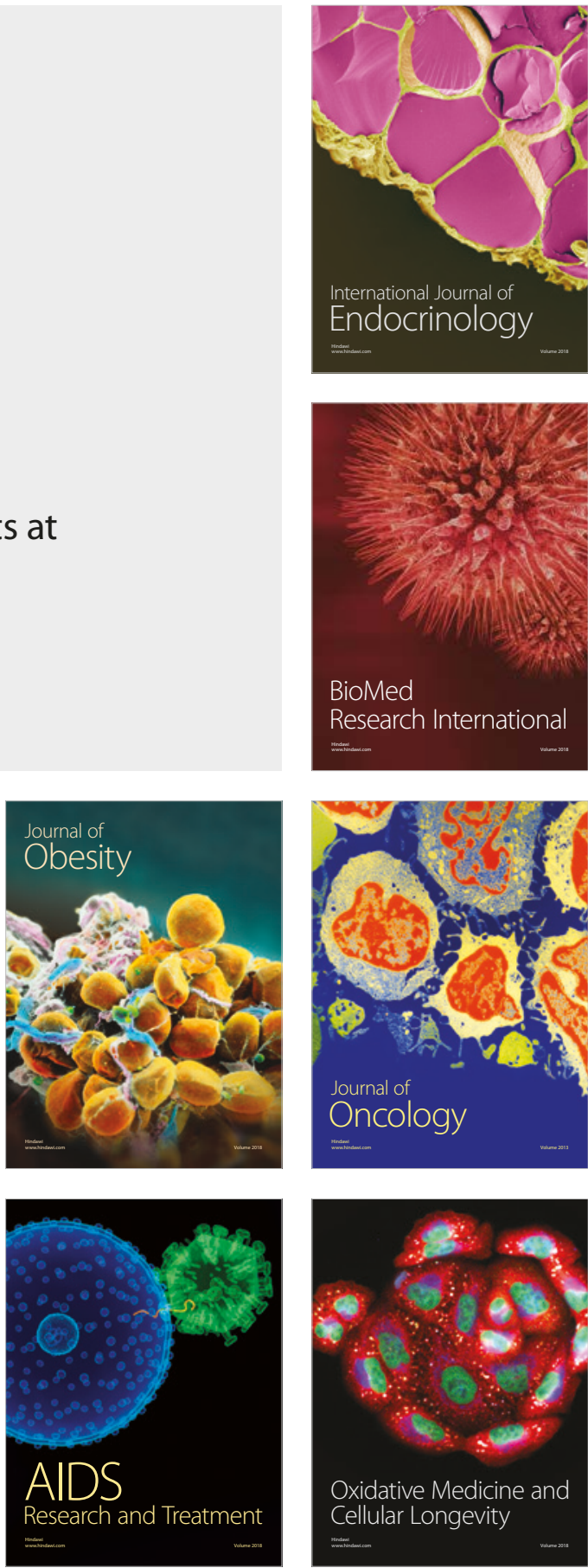